\title{
Predictive Value of POSSUM and ACPGBI Scoring in Mortality and Morbidity of Colorectal Resection: A Case-Control Study
}

\author{
Pascal H. E. Teeuwen - A. J. A. Bremers • \\ J. M. M. Groenewoud - C. J. H. M. van Laarhoven • \\ R. P. Bleichrodt
}

Received: 20 April 2010 / Accepted: 17 September 2010 /Published online: 9 October 2010

(C) The Author(s) 2010. This article is published with open access at Springerlink.com

\begin{abstract} assessed in the same way for comparison.

Presented to the Fourth Annual and Scientific Meeting of the

European Society of ColoProctology, Prague, Czech Republic,

September 2009.

P. H. E. Teeuwen · A. J. A. Bremers · C. J. H. M. van Laarhoven ·

R. P. Bleichrodt

Department of Surgery, Division of Gastro-Intestinal Surgery,

Radboud University Nijmegen Medical Centre,

Nijmegen, the Netherlands

J. M. M. Groenewoud

Medical Technology Assessment,

Radboud University Nijmegen Medical Centre,

Nijmegen, the Netherlands

P. H. E. Teeuwen $(\bowtie)$

Department of Surgery, Division of Abdominal Surgery,

Radboud University Nijmegen Medical Centre,

P.O. Box 9101, 6500 HBNijmegen, the Netherlands

e-mail: P.Teeuwen@chir.umcn.nl

Background Preoperative risk prediction to assess mortality and morbidity may be helpful to surgical decision making. The aim of this study was to compare mortality and morbidity of colorectal resections performed in a tertiary referral center with mortality and morbidity as predicted with physiological and operative score for enumeration of mortality and morbidity (POSSUM), Portsmouth POSSUM (P-POSSUM), and colorectal POSSUM (CR-POSSUM). The second aim of this study was to analyze the accuracy of different POSSUM scores in surgery performed for malignancy, inflammatory bowel diseases, and diverticulitis. POSSUM scoring was also evaluated in colorectal resection in acute vs. elective setting. In procedures performed for malignancy, the Association of Coloproctology of Great Britain and Ireland (ACPGBI) score was

Methods POSSUM, P-POSSUM, and CR-POSSUM predictor equations for mortality were applied in a retrospective casecontrol study to 734 patients who had undergone colorectal resection. The total group was assessed first. Second, the predictive value of outcome after surgery was assessed for malignancy $(n=386)$, inflammatory bowel diseases $(n=113)$, diverticulitis $(n=91)$, and other indications, e.g., trauma, endometriosis, volvulus, or ischemia ( $n=144)$. Third, all subgroups were assessed in relation to the setting in which surgery was performed: acute or elective. In patients with malignancy, the ACPGBI score was calculated as well. In all groups, receiver operating characteristic (ROC) curves were constructed.

Results POSSUM, P-POSSUM, and CR-POSSUM have a significant predictive value for outcome after colorectal surgery. Within the total population as well as in all four subgroups, there is no difference in the area under the curve between the 
POSSUM, P-POSSUM, and CR-POSSUM scores. In the subgroup analysis, smallest areas under the ROC curve are seen in operations performed for malignancy, which is significantly worse than for diverticulitis and in operations performed for other indications. For elective procedures, P-POSSUM and CR-POSSUM predict outcome significantly worse in patients operated for carcinoma than in patients with diverticulitis. In acute surgical interventions, CR-POSSUM predicts mortality better in diverticulitis than in patients operated for other indications. The ACPGBI score has a larger area under the curve than any of the POSSUM scores. Morbidity as predicted by POSSUM is most accurate in procedures for diverticulitis and worst when the indication is malignancy.

Conclusion The POSSUM scores predict outcome significantly better than can be expected by chance alone. Regarding the indication for surgery, each POSSUM score predicts outcome in patients operated for diverticulitis or other indications more accurately than for malignancy. The ACPGBI score is found to be superior to the various POSSUM scores in patients who have (elective) resection of colorectal malignancy.

Keywords Colorectal surgery $\cdot$ Abdominal surgery $\cdot$ Risk prediction · Surgical audit

\section{Introduction}

A large number of scoring systems to assess patient's risks of complications or death have been developed. The physiological and operative score for enumeration of mortality and morbidity (POSSUM) was reported to be the most appropriate of the scores currently available for general surgical practice. ${ }^{1}$ It uses 12 physiological and 6 operative variables to give a calculated risk of morbidity and death. POSSUM was intended to be used in a comparative surgical audit. It was applied to a number of surgical procedures, including vascular (V-POSSUM), ${ }^{2}$ oesophagogastric (O-POSSUM) ${ }^{3}$ or colorectal (CR-POSSUM $)^{4}$ surgery. Since the introduction of POSSUM in 1991 by Copeland et al., ${ }^{5}$ several studies have shown the POSSUM score to overestimate the mortality risk. ${ }^{6-8}$ The Portsmouth POSSUM was proposed to improve the predictive value of the initial model and has been primarily validated on patients undergoing vascular surgery. ${ }^{8-10}$

In 2003, the Association of Coloproctology of Great Britain and Ireland (ACPGBI) developed its own scoring system for surgical patients with colorectal cancer. The ACPGBI score is supposed to be easier to use than the three POSSUM models. ${ }^{11,12}$

The first aim of this study was to assess the role of POSSUM in surgical audit.

For this purpose, observed mortality and morbidity of colorectal resections performed in a tertiary referral centre were compared with mortality and morbidity as predicted with POSSUM, P-POSSUM, and CR-POSSUM scores and the ACPGBI score for patients operated on colorectal cancer.

The second aim of this study was to examine the accuracy of the various POSSUM scores for individual risk prediction in surgery performed for malignancy, inflammatory bowel diseases, and diverticulitis.

\section{Methods}

Inclusion

A retrospective case-control study was performed of all patients older than 15 years undergoing colorectal resection between January 2003 and January 2008 in the Radboud University Nijmegen Medical Centre. Surgical interventions were performed in an elective or acute setting. Acute operation was defined as surgical interventions after emergency admission. All other operations were classified as elective.

\section{Data Extraction}

The following data were extracted from the medical records: demographics, body mass index, coexistent morbidity, use of immunosuppressive medication, American Society of Anesthesiology (ASA) grade, indication and type of surgery, type of anastomosis, surgical reintervention (laparotomy, not radiological drainage), hospital stay, POSSUM, Portsmouth POSSUM (P-POSSUM), colorectal POSSUM (CR-POSSUM), morbidity predicted by POSSUM, postoperative mortality, and morbidity. Morbidity was defined as an unexpected event within 30 days after surgery, which was harmful for the patient's health and required a change of therapeutic strategy. Complications were classified as defined by POSSUM (http://www.sfar.org/scores2/possum2.html). Mortality was defined as any death within 30 days after surgical intervention. ACPGBI scores were calculated in patients who had colorectal resection for histological proven cancer.

\section{POSSUM and ACPGBI}

The POSSUM score comprises a physiological and an operative component. The physiological score is based on 12 variables to be assessed in different grades. The operative severity score uses six variables. The definitive POSSUM score is calculated with the physiological as well as the operative severity score. (http://www.sfar.org/ scores2/possum2.html, http://www.riskprediction.org.uk/) 
According to the literature on POSSUM, a normal grade was used if a variable was not available. The ACPGBI score, developed for oncologic resections, uses multifactorial logistic regression analysis to adjust for multiple risk factors, their interactions, and the clustering of adverse outcome. It is the result of a nationwide attempt in the UK to provide accurate risk adjusted outcomes involving over 8.000 patients from 77 centers. The ACPGBI score assesses five operative variables: age, cancer resection, ASA grade, Dukes' stage, and operative urgency (http://www.riskprediction.org.uk/).

\section{Outcome}

The (P-, CR-) POSSUM-predicted mortality and morbidity was compared with the observed mortality and morbidity. Subgroup analysis was made for operations performed for carcinoma, inflammatory bowel disease, diverticulitis, and other indications, e.g., trauma, endometriosis, volvulus, or ischemia. Primary outcome was mortality. Secondary outcome measures were morbidity, (POSSUM-) complications, and hospital stay.

\section{Statistical Analysis}

Receiver operating characteristic (ROC) curves were constructed of each group analyzed in order to examine sensitivity and specificity of each POSSUM score. Areas under the curves were compared within and between subgroups. Analysis of ROC curves is a widely accepted method to investigate the properties of a diagnostic test. The area under the curve (AUC) measures the ability of the test to correctly classify those with and without a disease. Comparing the AUC in several subgroups and for different POSSUM scores therefore is the most appropriate manner to distinguish the diagnostic abilities between certain POSSUM scores in a specific subgroup or between subgroups for a specific POSSUM score.

\section{Results}

From January 2003 to January 2008, colorectal resection was performed in 734 patients: 385 women $(52.5 \%)$ and 349 men $(47.5 \%)$. The mean age was 58.4 years $( \pm 16.8$; range, 16-96 years). In $386(52.5 \%)$ patients, the indication for surgery was malignancy, in $113(15.4 \%)$ inflammatory disease, and 91 (12.4\%) diverticulitis. One hundred forty-four (19.6\%) patients underwent colorectal surgery for other reasons: intestinal ischemia, volvulus, trauma, endometriosis, or carcinoma of urogenital or gynecologic origin. The most frequent surgical procedures were resection of the sigmoid (23.2\%) and right hemicolectomy (19.8\%; Table 1). Elective operations were performed in 555 patients (74.9\%), and 179

Table 1 Demographics and performed procedures in the different subgroups

\begin{tabular}{|c|c|c|c|c|c|c|c|c|c|}
\hline \multirow[t]{2}{*}{ Type of surgery } & \multicolumn{2}{|c|}{ Malignancy } & \multicolumn{2}{|c|}{$\begin{array}{l}\text { Inflammatory } \\
\text { bowel disease }\end{array}$} & \multicolumn{2}{|c|}{ Diverticulitis } & \multicolumn{2}{|l|}{ Other } & \multirow[t]{2}{*}{ Total } \\
\hline & Elective & Acute & Elective & Acute & Elective & Acute & Elective & Acute & \\
\hline$n$ & 335 & 51 & 93 & 20 & 50 & 41 & 77 & 67 & 734 \\
\hline Male & 177 & 25 & 40 & 5 & 21 & 21 & 24 & 34 & 349 \\
\hline Female & 158 & 26 & 53 & 15 & 29 & 20 & 53 & 33 & 385 \\
\hline Age (years) & $\begin{array}{l}65.4 \\
(12.8)^{\mathrm{a}}\end{array}$ & $\begin{array}{l}64.7 \\
(15.6)\end{array}$ & $\begin{array}{l}40.3 \\
(14.3)\end{array}$ & $\begin{array}{l}42.3 \\
(16.0)\end{array}$ & $\begin{array}{l}58.2 \\
(12.0)\end{array}$ & $\begin{array}{l}58.7 \\
(15.9)\end{array}$ & $\begin{array}{l}49.4 \\
(15.1)\end{array}$ & $\begin{array}{l}58.5 \\
(17.9)\end{array}$ & $\begin{array}{l}58.4 \\
(16.8)\end{array}$ \\
\hline $\begin{array}{l}\text { Body mass index } \\
\left(\mathrm{kg} / \mathrm{m}^{2}\right)\end{array}$ & $25.2(4.3)$ & $24.7(3.7)$ & $23.5(4.3)$ & $21.7(3.5)$ & $26.3(4.4)$ & $25.3(4.0)$ & $25.9(4.9)$ & $23.7(2.8)$ & $24.8(4.2)$ \\
\hline ASA & $2.1(0.7)$ & $2.2(0.7)$ & $1.9(0.5)$ & $2.2(0.8)$ & $2.0(0.8)$ & $1.9(0.8)$ & $2.1(0.8)$ & $2.7(1.0)$ & $2.1(0.7)$ \\
\hline $\begin{array}{l}\text { Right } \\
\text { hemicolectomy }\end{array}$ & 99 & 16 & 5 & 0 & 0 & 5 & 7 & 13 & 145 \\
\hline Left hemicolectomy & 25 & 6 & 3 & 1 & 4 & 0 & 21 & 5 & 65 \\
\hline $\begin{array}{l}\text { Transversum } \\
\text { resection }\end{array}$ & 11 & 3 & 2 & 1 & 2 & 0 & 5 & 9 & 33 \\
\hline Ileocoecal resection & 19 & 5 & 55 & 15 & 4 & 5 & 7 & 11 & 121 \\
\hline Sigmoid resection & 52 & 12 & 4 & 2 & 35 & 30 & 15 & 21 & 171 \\
\hline $\begin{array}{l}\text { (Sub-)total } \\
\text { colectomy }\end{array}$ & 35 & 4 & 17 & 1 & 1 & 0 & 6 & 5 & 69 \\
\hline $\begin{array}{l}\text { Rectosigmoid } \\
\text { resection }\end{array}$ & 94 & 5 & 7 & 0 & 4 & 1 & 16 & 3 & 130 \\
\hline
\end{tabular}

${ }^{a}$ Numbers in parentheses are the standard deviations 
Table 2 POSSUM scores, observed mortality and morbidity, re-intervention rate, and hospital stay in the different subgroups

\begin{tabular}{|c|c|c|c|c|c|c|c|c|c|c|c|}
\hline \multirow[t]{2}{*}{ Type of surgery } & \multicolumn{2}{|l|}{ Malignancy } & \multicolumn{2}{|c|}{$\begin{array}{l}\text { Inflammatory } \\
\text { bowel diseases }\end{array}$} & \multicolumn{2}{|c|}{ Diverticulitis } & \multicolumn{2}{|l|}{ Other } & \multicolumn{3}{|l|}{ Total } \\
\hline & Elective & Acute & Elective & Acute & Elective & Acute & Elective & Acute & Elective & Acute & Total \\
\hline$n$ & 335 & 51 & 93 & 20 & 50 & 41 & 77 & 67 & 555 & 179 & 734 \\
\hline \multicolumn{12}{|l|}{$\begin{array}{l}\text { Predicted mortality } \\
(\%)\end{array}$} \\
\hline POSSUM & 14.5 & 24.6 & 6.7 & 17.3 & 8.8 & 22.0 & 9.3 & 25.5 & 10.7 & 24.4 & 17.0 \\
\hline P-POSSUM & 5.4 & 12.2 & 2.3 & 5.7 & 2.8 & 10.8 & 2.9 & 12.4 & 3.7 & 11.2 & 5.9 \\
\hline CR-POSSUM & 3.9 & 8.7 & 1.3 & 3.0 & 2.1 & 8.4 & 1.6 & 7.9 & 2.5 & 7.7 & 4.0 \\
\hline $\begin{array}{l}\text { Observed } \\
\text { mortality (\%) }\end{array}$ & $27(8.1)$ & $7(13.5)$ & $1(1.1)$ & $1(5.0)$ & $3(6.0)$ & $6(14.6)$ & $4(5.2)$ & $16(23.9)$ & $35(6.3)$ & $30(16.7)$ & $65(8.9)$ \\
\hline $\begin{array}{l}\text { Predicted } \\
\text { morbidity (\%) }\end{array}$ & 50.7 & 64.1 & 29.6 & 45.2 & 35.9 & 58.8 & 35.7 & 64.7 & 40.1 & 61.0 & 46.0 \\
\hline $\begin{array}{l}\text { Observed } \\
\text { morbidity (\%) }\end{array}$ & $\begin{array}{l}130 \\
(38.8)\end{array}$ & 18 & $\begin{array}{l}32 \\
(34.4)\end{array}$ & $\begin{array}{l}10 \\
(50.0)\end{array}$ & $\begin{array}{l}18 \\
(36.0)\end{array}$ & $\begin{array}{l}16 \\
(39.0)\end{array}$ & $\begin{array}{l}32 \\
(41.6)\end{array}$ & $\begin{array}{l}33 \\
(49.3)\end{array}$ & $\begin{array}{l}212 \\
\quad(38.2)\end{array}$ & $\begin{array}{l}77 \\
(43.0)\end{array}$ & $\begin{array}{l}289 \\
(39.4)\end{array}$ \\
\hline Wound hemorrhage & 2 & & & & & & & & 2 & & 2 \\
\hline Deep hemorrhage & 6 & 3 & 1 & & 1 & & 1 & 1 & 9 & 4 & 13 \\
\hline Chest infection & 14 & 6 & 5 & 2 & 2 & 1 & 5 & 3 & 26 & 12 & 38 \\
\hline Wound infection & 19 & 7 & 8 & 1 & 7 & 4 & 4 & 7 & 38 & 19 & 57 \\
\hline Urinary infection & 17 & 6 & 3 & & 1 & 1 & 3 & 3 & 24 & 10 & 34 \\
\hline Deep infection & 15 & 2 & 6 & & 4 & 4 & 8 & 8 & 33 & 14 & 47 \\
\hline Septicaemia & 9 & 8 & 1 & 2 & 1 & 3 & 1 & 4 & 12 & 17 & 29 \\
\hline $\begin{array}{l}\text { Pyrexia of } \\
\text { unknown origin }\end{array}$ & & & 1 & & & & & & 1 & & 1 \\
\hline Wound dehiscence & 9 & 1 & 2 & 2 & & 1 & & 4 & 11 & 8 & 19 \\
\hline $\begin{array}{l}\text { Deep venous } \\
\text { thrombosis and } \\
\text { pulmonary embolus }\end{array}$ & 6 & & 1 & & & & 1 & & 8 & & 8 \\
\hline Cardiac failure & 8 & 2 & & 4 & 1 & 2 & & 2 & 9 & 10 & 19 \\
\hline $\begin{array}{l}\text { Impaired renal } \\
\text { function }\end{array}$ & 3 & 1 & & 1 & & 1 & & 1 & 3 & 4 & 7 \\
\hline Hypotension & 2 & & & 1 & & 1 & & & 2 & 2 & 4 \\
\hline $\begin{array}{l}\text { Respiratory } \\
\text { failure }\end{array}$ & 2 & 3 & 1 & 1 & 1 & 2 & 2 & 4 & 6 & 10 & 16 \\
\hline $\begin{array}{l}\text { Anastomotic } \\
\text { leakage }\end{array}$ & 29 & 5 & 8 & 1 & 4 & 2 & 4 & 9 & 45 & 17 & 62 \\
\hline Total complications & 141 & 44 & 37 & 15 & 22 & 22 & 29 & 46 & 229 & 127 & 356 \\
\hline Re-intervention & 56 & 11 & 16 & 5 & 9 & 10 & 20 & 25 & 101 & 51 & 152 \\
\hline $\begin{array}{l}\text { Hospital stay } \\
\text { (median days) } \\
\text { (range) }\end{array}$ & $10(2-127)$ & $11(2-150)$ & $8(1-55)$ & $7(1-64)$ & $9(3-57)$ & $8(3-61)$ & $12(1-59)$ & $15(5-132)$ & $10(1-127)$ & $12(1-150)$ & $10(1-150)$ \\
\hline
\end{tabular}

(25.1\%) were operated in an acute setting. The number of patients who had one or more surgical re-interventions was $152(20.7 \%$; Table 2).

Morbidity was 289 in 734 (39.4\%). The total number of complications amounted 356, so the mean number of complications per patient is 1.7. Among electively operated patients, $212(38.2 \%)$ had one or more complications. Seventy-seven $(43.0 \%)$ patients, operated on in an acute setting, had an unfavorable postoperative course. The most common complications were anastomotic leakage, surgical site infection, pulmonary, and urinary infections. Mean morbidity as predicted by POSSUM was $46.0 \%$ (Table 2 ).
Sixty-five patients $(8.9 \%)$ died within 30 days after surgery (Tables 2 and 3 ). The predicted mortality by POSSUM was $17.0 \%$, Portsmouth POSSUM 5.9\%, and colorectal-POSSUM $4.0 \%$. In the total population as well as the subgroups (except the group with patients operated for inflammatory bowel diseases), POSSUM, P-POSSUM, and CR-POSSUM had a significantly larger predictive value for outcome after (elective and acute) colorectal surgery than can be expected by chance alone $(P<0.001)$. Within the total population (Fig. 1), as well as in all four subgroups (Fig. 2), there is no difference in the area under the curve between the POSSUM, P-POSSUM, and CR- 
Table 3 Causes of mortality

\begin{tabular}{|c|c|c|c|c|c|c|c|c|c|c|c|}
\hline \multirow[t]{2}{*}{ Type of surgery } & \multicolumn{2}{|c|}{ Malignancy } & \multicolumn{2}{|c|}{$\begin{array}{l}\text { Inflammatory } \\
\text { bowel diseases }\end{array}$} & \multicolumn{2}{|c|}{ Diverticulitis } & \multicolumn{2}{|l|}{ Other } & \multicolumn{3}{|l|}{ Total } \\
\hline & Elective & Acute & Elective & Acute & Elective & Acute & Elective & Acute & Elective & Acute & Total \\
\hline Observed mortality & 27 & 7 & 1 & 1 & 3 & 6 & 4 & 16 & 35 & 30 & 65 \\
\hline Respiratory insufficiency & 2 & 2 & & & & 2 & 1 & 5 & 3 & 9 & 12 \\
\hline Cardiac failure & 3 & & 1 & & & & & & 4 & & 4 \\
\hline \multicolumn{12}{|l|}{ Abdominal sepsis } \\
\hline Leakage & 5 & 2 & & 1 & 1 & & & 3 & 6 & 6 & 12 \\
\hline Disease & & 1 & & & 1 & 2 & 1 & 2 & 2 & 5 & 7 \\
\hline Ischemia & 2 & & & & & 1 & & 2 & 2 & 3 & 5 \\
\hline Change of treatment strategy ${ }^{a}$ & 7 & 2 & & & & 1 & 1 & 3 & 8 & 6 & 14 \\
\hline Unknown & 5 & & & & & & 1 & & 6 & & 6 \\
\hline Cerebrovascular accident & 1 & & & & & & & 1 & 1 & 1 & 2 \\
\hline Bleeding & 1 & & & & 1 & & & & 2 & & 2 \\
\hline Transfusion reaction & 1 & & & & & & & & 1 & & 1 \\
\hline
\end{tabular}

${ }^{\mathrm{a}}$ Due to metastasis, progressive hematological malignancy, loss of perspective

POSSUM scores. In the subgroup analysis, smallest areas under the ROC curve are seen in operations performed for malignancy $(0.65 ; 0.65 ; 0.65)$. This is significantly worse than in the diverticulitis group $(0.86, P=0.01 ; 0.88, P<$ 0.001 ; and $0.89, P=0.02$, respectively) and in operations performed for other indications $(0.80, P=0.03 ; 0.80, P=0.03$; and $0.79, P=0.03$, respectively). For elective procedures, PPOSSUM and CR-POSSUM predictions are significantly worse in patients operated for carcinoma than in patients with diverticulitis ( 0.61 vs. $0.85, P=0.02$, and 0.63 vs. 0.89 , $P<0.001$, respectively). For acute surgical interventions, CR-

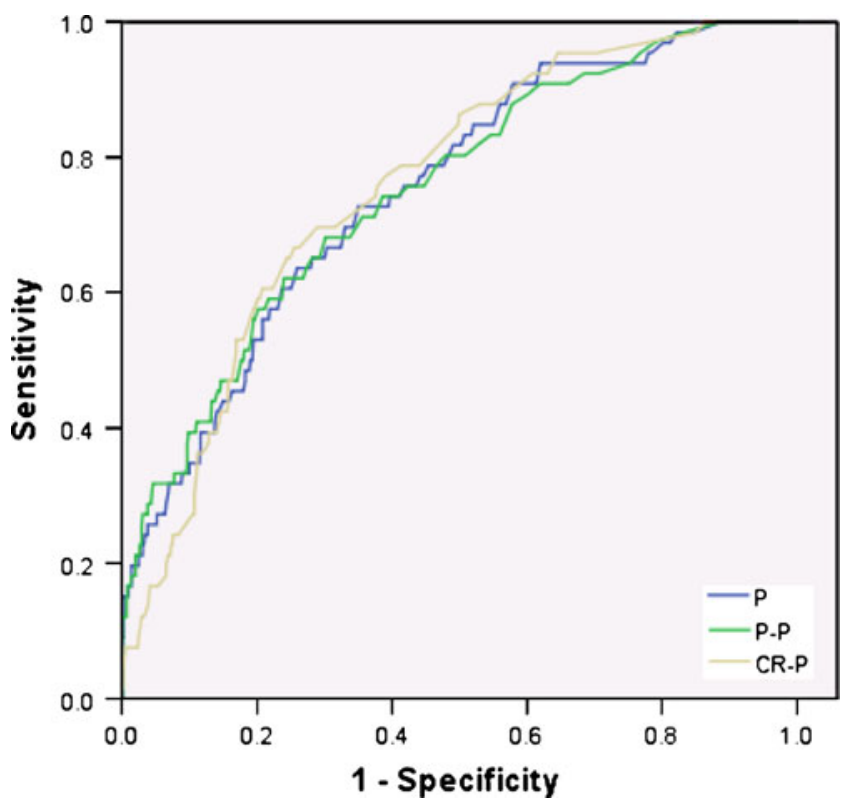

Fig. 1 ROC total group
POSSUM predicts mortality better in diverticulitis than in patients operated for other indications $(0.89$ vs. $0.66, P=$ $0.02)$.

Within the group operated on carcinoma, 190 patients had a known histology and the ACPGBI score was calculated (Table 4). The observed mortality in this group was $4.7 \%$ and morbidity $30.5 \%$. The ACPGBI score predicted a mortality rate of $5.55 \%( \pm 4.48)$. Twenty-seven of the 190 performed procedures were in an acute setting.

The ACPGBI score, designed for oncologic colorectal resections, has a larger area under the curve than any of the POSSUM scores $(0.854, P<0.001$; Fig. 3$)$. The same applies to oncologic resections performed in the elective setting $(P<0.001)$. ACPGBI was found not to be superior to POSSUM $(P=0.83)$, P-POSSUM $(P=0.56)$, and CRPOSSUM $(P=0.84)$ in acute oncologic surgery. Fourteen out of 65 patients $(21.5 \%)$ died after a change in treatment policy due to extensive oncological disease $(n=11)$ or the lack of perspective on a acceptable outcome $(n=3)$. Morbidity as predicted by POSSUM is most accurate in procedures for diverticulitis (0.757) and worst when the indication is malignancy (0.532).

\section{Discussion}

When POSSUM is applied for individual risk prediction in patients undergoing colorectal resections for malignancy, inflammatory bowel diseases, or diverticulitis, the most accurate mortality predictions with any of the POSSUM scores was in patients with diverticulitis. The ACPGBI score is found to be superior to POSSUM 

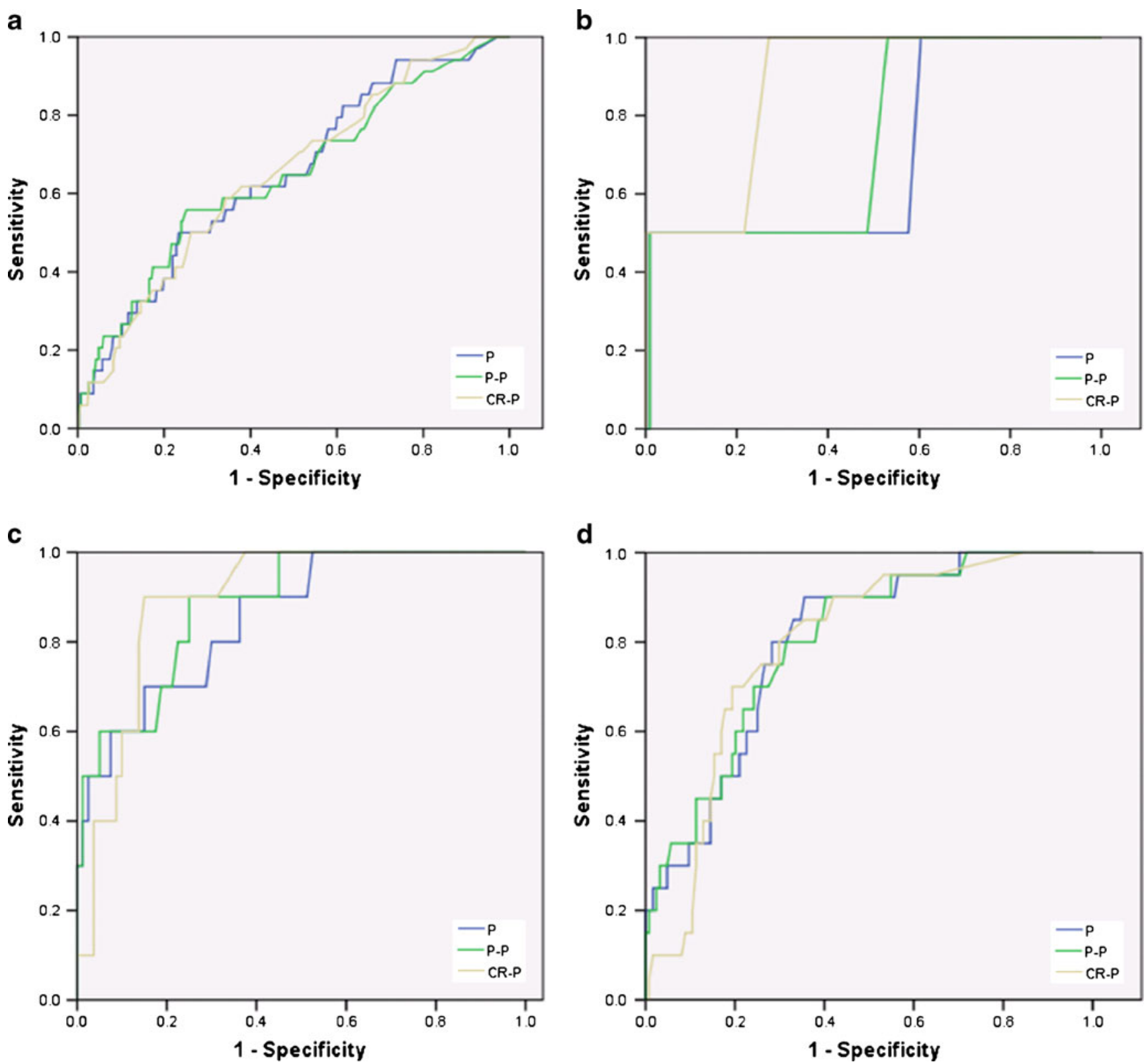

Fig. 2 Subgroup analysis: malignancy (a), inflammatory bowel disease (b), diverticulitis (c), and other (d)

Table 4 ACPGBI score in 190 patients with carcinoma

\begin{tabular}{ll}
\hline & Carcinoma \\
\hline$N$ & 190 \\
Male/female & $108: 82$ \\
Age (mean $\pm \mathrm{SD}$, range) & $66 \pm 12.2(33-89)$ \\
Elective/acute & $163: 27$ \\
ASA (mean \pm SD) & $2.11 \pm 0.73$ \\
Observed mortality (\%) & $9(4.7)$ \\
Observed morbidity (\%) & $58(30.5)$ \\
ACPGBI score (mean $\pm \mathrm{SD})$ & $5.55 \pm 4.48$ \\
\hline
\end{tabular}

scoring in patients who had (elective) resections of colorectal cancers.

\section{POSSUM and Surgical Audit}

One of the main concerns in POSSUM scoring is its overestimation of mortality. The mortality rate predicted by POSSUM (17.0\%) was double the observed mortality in our total study population $(8.9 \%)$. The drawbacks of the original POSSUM score led to the development of Portsmouth POSSUM and colorectal POSSUM. In our study, both scores underestimated the mortality risk $(5.9 \%$ and $4.0 \%$, respectively). Several reasons can be pointed out. 


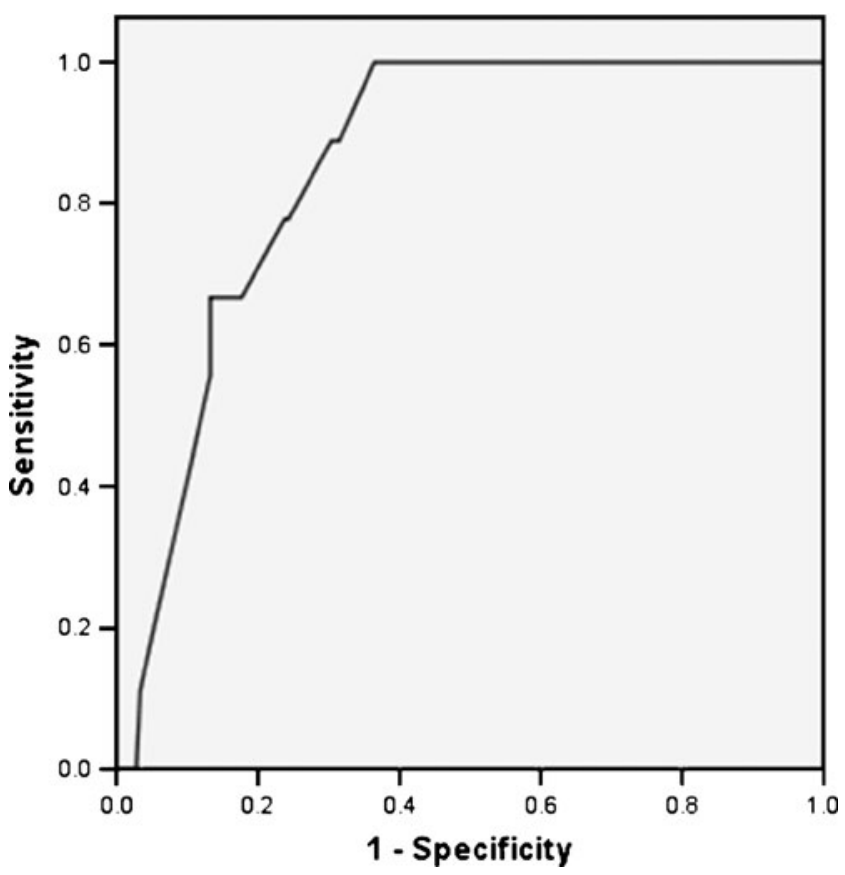

Fig. 3 Predictive value of ACPGBI score on outcome after colorectal resection for malignancy

First, the primary studies on POSSUM extend their analyses back to the early 1990s and are less likely to represent current practice. ${ }^{13}$ Better understanding of dis- eases and improvements in diagnostic and therapeutic techniques have lowered mortality rates. Regarding surgical practice, developments such as laparoscopic intervention and enhanced recovery programs have caused a decrease in mortality ${ }^{14}$ Hence, mathematical prediction models may be outdated. Law et al. ${ }^{15}$ reported overprediction of the POSSUM scores for laparoscopic colorectal resections. In converted controls, however, POSSUM scoring was reliable, which implies a discrepancy in predictive value due to operative technique. Second, POSSUM was originally developed with patients in the UK. However, outcomes may vary with other countries or high-volume specialized centers. ${ }^{16,17}$ Third, surgery got more and more specialized over time. The original POSSUM score was designed for the general surgical patient. The accuracy of these models is under discussion due to the use of mixed patient populations. More recently, several studies specify risk prediction for different subgroups. ${ }^{13}$

In our opinion, the main argument against the use of POSSUM in surgical audit is found in the validation as a risk prediction model. Nearly all reports on POSSUM scoring validate the score on their own series, which leads to different conclusions of reports regarding overor underpredicting of the scores. Patient selection, local facilities, and skills may be confounding factors. This is illustrated by a broad range of observed vs. expected

Table 5 Observed/expected ratios in the literature

\begin{tabular}{|c|c|c|c|c|c|c|c|c|}
\hline \multirow[t]{2}{*}{ Author } & \multicolumn{2}{|l|}{ POSSUM } & \multicolumn{2}{|l|}{ P-POSSUM } & \multicolumn{2}{|l|}{ CR-POSSUM } & \multirow[t]{2}{*}{ ACPGBI } & \multirow[t]{2}{*}{ Mortality } \\
\hline & POSSUM & $\mathrm{O} / \mathrm{E}$ & P-POSSUM & $\mathrm{O} / \mathrm{E}$ & CR-POSSUM & $\mathrm{O} / \mathrm{E}$ & & \\
\hline \multicolumn{9}{|l|}{ Malignancy } \\
\hline Oomen ${ }^{29}$ & 10.6 & 0.16 & 3.8 & 0.45 & 3.8 & 0.45 & & 1.7 \\
\hline $\operatorname{Slim}^{7}$ & 13.3 & 0.28 & 5.5 & 0.67 & & & & 3.7 \\
\hline Ferjani $^{11}$ & 12.7 & 0.80 & 4.4 & 2.32 & 9.6 & 1.06 & 8.1 & 10.2 \\
\hline $\operatorname{Ren}^{38}$ & 5.6 & 0.18 & 2.8 & 0.35 & 4.8 & 0.20 & & 1.0 \\
\hline Horzic $^{39}$ & & & 6.7 & 1.24 & 7.5 & 1.11 & & 8.3 \\
\hline Ugolini $^{40}$ & & & 7.9 & 0.79 & 9.14 & 0.68 & 19.4 & 6.3 \\
\hline Menon $^{9}$ & & & 15.6 & 0.56 & & & & 8.7 \\
\hline $\mathrm{Tez}^{27}$ & & & 9.0 & 0.77 & 7.8 & 0.88 & & 6.9 \\
\hline Bromage $^{26}$ & 1.9 & 3.37 & & 1.59 & & 1.25 & & 6.5 \\
\hline Ibister $^{41}$ & 6.7 & 0.21 & 3.5 & 0.40 & & & & 1.4 \\
\hline Poon $^{42}$ & & & 15.0 & 0.75 & & & & 11.3 \\
\hline $\operatorname{Tan}^{43}$ & & & & & 11.2 & 0.14 & 5.4 & 1.6 \\
\hline Ugolini $^{44}$ & & & 11.2 & 0.92 & 13.1 & 0.79 & & 10.3 \\
\hline $\mathrm{Can}^{45}$ & 13.4 & 0.27 & 5.2 & 0.69 & & & & 3.6 \\
\hline \multicolumn{9}{|l|}{ Diverticulitis } \\
\hline Oomen $^{29}$ & 6.3 & 0.52 & 2.2 & 1.50 & 2.3 & 1.43 & & 3.3 \\
\hline $\operatorname{Slim}^{7}$ & 6.9 & 0.38 & 2.8 & 0.93 & & & & 2.6 \\
\hline Oomen ${ }^{46}$ & 7.7 & 0.74 & & & & & & 5.7 \\
\hline Constatinides $^{28}$ & 21.9 & 0.49 & 10.5 & 1.03 & 10.0 & 1.08 & & 10.8 \\
\hline
\end{tabular}




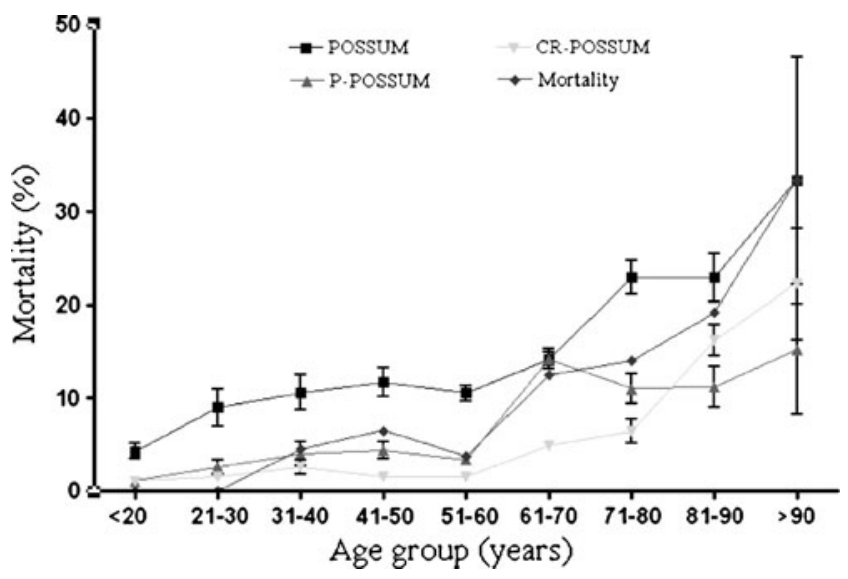

Fig. 4 Observed and predicted mortality related to age group

ratios in the literature (Table 5). In our opinion, risk prediction models need to be validated to a "gold standard" in order to allow comparative audit. Since reports on surgical outcome differ and definitions of adverse outcome may vary, this desired standard may be unrealistic. Russell ${ }^{18}$ and Ferjani ${ }^{11}$ have stated that a system with standard definitions is mandatory before clinical performance can be compared between health care systems and institutions. A proper and uniform definition of mortality is essential in risk prediction. Most studies on POSSUM describe mortality as primary outcome only. As Brooks et al. ${ }^{6}$ pointed out, the majority of surgical procedures carry a low risk of death. However, along with decreasing mortality rates, the relevance of predicting morbidity is increasing. POSSUM also predicts the chance that a patient develops one or more complications with only moderate accuracy (area under the curve $0.53-0.76$ ).

Cumulative sum techniques (CUSUM), described in 1954 by Page and its first introduction in surgical practice in 1994, might encounter the drawbacks mentioned above. This technique allows one to judge whether an observed variation in performance is acceptable (i.e., probably due to chance) or whether the variation is greater than what could be expected from random variation and thus may be a cause for concern. However, acceptable and unacceptable outcome rate as type I and II error rate has to be defined first. CUSUM is helpful in the evaluation of a clinical procedure before its implementation without the drawbacks of a randomized clinical trial. Plotting of the cumulative sum has been proven valuable for examining sequential measures, detecting changes over time, and is applied as a means of assessing surgical skills of trainees. Continued surveillance using the CUSUM allows the early detection of factors that lead to an increased failure rate. Quality control and objective and quantified recording of the findings meet the recommended criteria for medical audit. ${ }^{19-23}$

POSSUM and Individual Risk Prediction

By tailoring POSSUM to patient- and procedure-specific assessment, it becomes a tool that can help inform the individual patient on a certain procedure and the risk on adverse outcome. Several studies reported the value of POSSUM in surgery for colorectal cancer. ${ }^{9,17,24-27}$ Tekkis et al. ${ }^{4}$ developed the colorectal POSSUM and differentiated for elective or acute procedures and procedures performed for malignancy or no malignancy. Constantinides et al. ${ }^{28}$ studied the value of POSSUM scoring in patients with complicated diverticulitis and concluded that CR-POSSUM was more accurate to predict outcome than (P-)POSSUM. Oomen et al. ${ }^{29}$ retrospectively compared the different POSSUM scores in 241 patients undergoing elective resection of the sigmoid for carcinoma or diverticular disease. Although patients with diverticular disease had a higher score than patients with malignancy, mortality rate did not differ. It was concluded that none of the POSSUM scores was predictive of disease-specific mortality. However, we found significant differences in POSSUM scoring related to the indication of surgery. All POSSUM scores predicted outcome more accurately in patients with diverticular disease than in patients operated on colorectal cancer. Within the subgroup of patients with diverticular disease, we could not define a superior POSSUM score. POSSUM, P-POSSUM, and CR-POSSUM scores also predicted equally in patients with colorectal cancer. In our opinion, disease-specific patient and operative variables should be included to improve the scores. Furthermore, patients are getting older and preexistent morbidity is likely to increase. In our series, a larger variation of the various POSSUM scores is found in octogenarians (Fig. 4). This is in accordance with Slim et al. ${ }^{6}$ who studied risk prediction by POSSUM and the AFC index (Association Française de Chirurgie). It is unclear whether the introduction of more extensive cardiac and pulmonary risk indexes might further improve the predictive accuracy of POSSUM scoring. It may further complicate POSSUM scoring. The AFC index is a simpler instrument without any mathematical formulas. It uses only four independent preoperative factors and is found to be as predictive as P-POSSUM.

\section{Malignant Colorectal Disease}

All mean POSSUM scores were higher in the carcinoma group than in diverticulitis, whilst observed mortality rates were comparable.

ACPGBI scoring was found to be superior in predicting mortality after resection of colorectal cancer both in elective 
and acute interventions, which is consistent with the literature. ${ }^{11,30}$ Thirty-seven out of 386 patients operated for colorectal malignancy $(9.6 \%)$ had known metastasis. Mortality rate was $29.7 \%$ (11/37); all patients died as consequence of a change to tender loving care due to a lack of perspective on a reasonable outcome (Table 3). Mean POSSUM, P-POSSUM, and CR-POSSUM score in the deceased group were lower than in patients who survived (respectively 11.7 vs. $21.1, P=0.02 ; 3.9$ vs. $7.8, P=0.05$; and 2.5 vs. $3.6, P=0.07$ ). Although based on a small population, these results demonstrate the insufficient predictive value of POSSUM scoring in patients with extensive oncological disease. Patients with colorectal cancer are likely to be immunosuppressed due to elderly age, nutritional status, and the colorectal cancer itself. ${ }^{31,32}$ The Dukes' classification is too coarse to reflect today's pathologists' power to detect disease parameters in cancer. ${ }^{29}$ Implementation of nutritional status in POSSUM might help improve the area under the curve in malignancy. ${ }^{4,726}$ Both suggestions for improving POSSUM scoring need further research.

Question remains whether or not these patients have to be taken into account in validating risk prediction models. Wellinformed patients with advanced cancers may trade off a short-term risk in exchange for cancer cure. In this population, the risks of resectional surgery may outweigh the benefits of a simpler and possibly safer palliative operation, but this requires reliable risk estimations. ${ }^{12}$

\section{Inflammatory Bowel Diseases}

No previous studies evaluated POSSUM scoring in patients with inflammatory bowel disease. Due to the view of the physiological variables included in POSSUM, the younger, relatively healthy patient with inflammatory bowel disease is likely to have a different score than the elderly with an extensive medical history operated for colorectal carcinoma. Patients with colitis often have an increased white blood cell count and low levels of hemoglobin or albumin, reflecting disease activity. Furthermore, these patients often use immunosuppressive medication and have a poor nutritional status, which is found to increase adverse outcome after surgery. ${ }^{33} \mathrm{We}$ found lowest POSSUM scores in this subgroup for mortality, which corresponded with the observed death rate. However, morbidity was underestimated by POSSUM. Younger age and the absence of cardiopulmonary comorbidity may explain the capability to overcome postoperative complications. POSSUM scoring for IBD may require a more prominent role of age, use of medication, nutritional status, level of hemoglobin, albumin, and white blood cell count. ${ }^{26}$ Calibration of POSSUM for patients with inflammatory bowel disease may be hard since recent review showed improved outcome of surgery to be highly dependent on accurate timing of the surgery and better perioperative care. ${ }^{34}$

\section{Diverticular Disease}

The most reliable predictions as demonstrated by the highest areas under the curve were found for patients with diverticulitis. The observed mortality was considerably higher than in patients operated for inflammatory bowel diseases and almost similar to patients with carcinomas. Patients with diverticulitis had the highest body mass indexes and were operated urgently more often, both associated with an increased complication rate. ${ }^{35-37}$ Leftsided resections were more frequently performed in patients with diverticular disease $(81.3 \%)$ than in malignancy $(50.3 \%)$ and inflammatory bowel diseases $(15 \%)$. Leftsided resections are known to cause more complications. ${ }^{33}$ Another explanation may be patient selection. High-risk patients with diverticular disease may be withheld from surgery, whereas a malignant indication for surgery will not allow a conservative treatment strategy. Accurate definition of high-risk patients is essential. Body mass index, operative urgency, and degree of peritoneal contamination may be important variables in order to calibrate POSSUM scoring for diverticulitis.

This study questions the role of POSSUM for the comparison of clinical performance between health care institutes. Poor definitions of surgical outcome and problematic validation of this risk prediction model are the main objections to use POSSUM for surgical audit.

In its present form, POSSUM scoring should not be used for medical decision making in individual patients either.

Future investigation needs to point out whether further calibration of POSSUM is feasible, or that alternative risk prediction models need to be developed. One solution may be for models to be more disease-specific.

Open Access This article is distributed under the terms of the Creative Commons Attribution Noncommercial License which permits any noncommercial use, distribution, and reproduction in any medium, provided the original author(s) and source are credited.

\section{References}

1. Jones HJ, de Cossart L. Risk scoring in surgical patients. $\mathrm{Br} J$ Surg 1999;86(2):149-57.

2. Lazarides MK, Arvanitis DP, Drista $\mathrm{H}$ et al. POSSUM and APACHE II scores do not predict the outcome of ruptured infrarenal aortic aneurysms. Ann Vasc Surg 1997;11(2):155-8.

3. Tekkis PP, McCulloch P, Poloniecki JD et al. Risk-adjusted prediction of operative mortality in oesophagogastric surgery with O-POSSUM. Br J Surg 2004;91(3):288-95.

4. Tekkis PP, Prytherch DR, Kocher HM et al. Development of a dedicated risk-adjustment scoring system for colorectal surgery (colorectal POSSUM). Br J Surg 2004;91(9):1174-82.

5. Copeland GP, Jones D, Walters M. POSSUM: a scoring system for surgical audit. Br J Surg 1991;78(3):355-60. 
6. Brooks MJ, Sutton R, Sarin S. Comparison of Surgical Risk Score, POSSUM and p-POSSUM in higher-risk surgical patients. Br J Surg 2005;92(10):1288-92.

7. Slim K, Panis Y, Alves A et al. Predicting postoperative mortality in patients undergoing colorectal surgery. World J Surg 2006;30 (1):100-6.

8. Whiteley MS, Prytherch DR, Higgins B et al. An evaluation of the POSSUM surgical scoring system. Br J Surg 1996;83 (6):812-5.

9. Menon KV, Farouk R. An analysis of the accuracy of P-POSSUM scoring for mortality risk assessment after surgery for colorectal cancer. Colorectal Dis 2002;4(3):197-200.

10. Prytherch DR, Whiteley MS, Higgins B et al. POSSUM and Portsmouth POSSUM for predicting mortality. Physiological and Operative Severity Score for the enUmeration of Mortality and morbidity. Br J Surg 1998;85(9):1217-20.

11. Ferjani AM, Griffin D, Stallard N et al. A newly devised scoring system for prediction of mortality in patients with colorectal cancer: a prospective study. Lancet Oncol 2007;8(4):317-22.

12. Tekkis PP, Poloniecki JD, Thompson MR et al. Operative mortality in colorectal cancer: prospective national study. BMJ 2003;327(7425):1196-201.

13. Poirier M, Espat NJ. Scoring systems: predictive accuracy through specificity. Lancet Oncol 2007;8(4):282-3.

14. Teeuwen PH, Bleichrodt RP, Strik $\mathrm{C}$ et al. Enhanced recovery after surgery (ERAS) versus conventional postoperative care in colorectal surgery. J Gastrointest Surg 2010;14:88-95.

15. Law WL, Lam CM, Lee YM. Evaluation of outcome of laparoscopic colorectal resection with POSSUM, Portsmouth POSSUM and colorectal POSSUM. Br J Surg 2006;93(1):94-9.

16. Bennett-Guerrero E, Hyam JA, Shaefi $\mathrm{S}$ et al. Comparison of PPOSSUM risk-adjusted mortality rates after surgery between patients in the USA and the UK. Br J Surg 2003;90(12):1593-8.

17. Senagore AJ, Warmuth AJ, Delaney CP et al. POSSUM, pPOSSUM, and Cr-POSSUM: implementation issues in a United States health care system for prediction of outcome for colon cancer resection. Dis Colon Rectum 2004;47(9):1435-41.

18. Russell EM, Bruce J, Krukowski ZH. Systematic review of the quality of surgical mortality monitoring. Br J Surg 2003;90 (5):527-32.

19. Biau DJ, Resche-Rigon M, Godiris-Petit G et al. Quality control of surgical and interventional procedures: a review of the CUSUM. Qual Saf Health Care 2007;16(3):203-7.

20. Yap CH, Colson ME, Watters DA. Cumulative sum techniques for surgeons: a brief review. ANZ J Surg 2007;77(7):583-6.

21. Lim TO, Soraya A, Ding LM et al. Assessing doctors' competence: application of CUSUM technique in monitoring doctors' performance. Int J Qual Health Care 2002;14(3):251-8.

22. Chang WR, McLean IP. CUSUM: a tool for early feedback about performance? BMC Med Res Methodol 2006;6:8.

23. Grunkemeier GL, Wu YX, Furnary AP. Cumulative sum techniques for assessing surgical results. Ann Thorac Surg 2003;76(3):663-7.

24. Al-Homoud S, Purkayastha S, Aziz O et al. Evaluating operative risk in colorectal cancer surgery: ASA and POSSUM-based predictive models. Surg Oncol 2004;13(2-3):83-92.

25. Anwar MA, D'Souza F, Coulter R et al. Outcome of acutely perforated colorectal cancers: experience of a single district general hospital. Surg Oncol 2006;15(2):91-6.

26. Bromage SJ, Cunliffe WJ. Validation of the CR-POSSUM riskadjusted scoring system for major colorectal cancer surgery in a single center. Dis Colon Rectum 2007;50(2):192-6.

27. Tez M, Yoldas O, Gocmen E et al. Evaluation of P-POSSUM and CR-POSSUM scores in patients with colorectal cancer undergoing resection. World J Surg 2006;30(12):2266-9.
28. Constantinides VA, Tekkis PP, Senapati A. Comparison of POSSUM scoring systems and the surgical risk scale in patients undergoing surgery for complicated diverticular disease. Dis Colon Rectum 2006;49(9):1322-31.

29. Oomen JL, Cuesta MA, Engel AF. Comparison of outcome of POSSUM, p-POSSUM, and cr-POSSUM scoring after elective resection of the sigmoid colon for carcinoma or complicated diverticular disease. Scand J Gastroenterol 2007;42(7):841-7.

30. Metcalfe MS, Norwood MG, Miller AS et al. Unreasonable expectations in emergency colorectal cancer surgery. Colorectal Dis 2005;7(3):275-8.

31. Evans C, Dalgleish AG, Kumar D. Review article: immune suppression and colorectal cancer. Aliment Pharmacol Ther 2006;24(8):1163-77.

32. Evans CF, Galustian C, Bodman-Smith $M$ et al. The effect of colorectal cancer upon host peripheral immune cell function. Colorectal Dis 2010;12:561-9.

33. Kingham TP, Pachter HL. Colonic anastomotic leak: risk factors, diagnosis, and treatment. J Am Coll Surg 2009;208(2):269-78.

34. Teeuwen PH, Stommel MW, Bremers AJ et al. Colectomy in patients with acute colitis: a systematic review. $J$ Gastrointest Surg 2009;13(4):676-86.

35. Gendall KA, Raniga S, Kennedy R et al. The impact of obesity on outcome after major colorectal surgery. Dis Colon Rectum 2007;50(12):2223-37.

36. Benoist S, Panis Y, Alves A et al. Impact of obesity on surgical outcomes after colorectal resection. Am J Surg 2000;179(4):27581.

37. Engel AF, Oomen JL, Knol DL et al. Operative mortality after colorectal resection in the Netherlands. Br J Surg 2005;92 (12):1526-32.

38. Ren L, Upadhyay AM, Wang L, et al. Mortality rate prediction by Physiological and Operative Severity Score for the Enumeration of mortality and morbidity (POSSUM), Portsmouth POSSUM and Colorectal POSSUM and the development of new scoring systems in Chinese colorectal cancer patients. Am J Surg 2009;198(1):31-8.

39. Horzic M, Kopljar M, Cupurdija $\mathrm{K}$, et al. Comparison of $\mathrm{P}$ POSSUM and CR-POSSUM scores in patients undergoing colorectal cancer resection. Arch Surg 2007;142(11):1043-8.

40. Ugolini G, Rosati G, Montroni I, et al. An easy-to-use solution for clinical audit in colorectal cancer surgery. Surgery 2009;145 (1):86-92.

41. Ibister WH, Al-Sanea N. POSSUM: a re-evaluation in patients undergoing surgery for rectal cancer. The physiological and operative severity score for enumeration of mortality and morbidity. ANZ J Surg 2002;72(6):421-5.

42. Poon JT, Chan B, Law WL. Evaluation of P-POSSUM in surgery for obstructing colorectal cancer and correlation of the predicted mortality with different surgical options. Dis Colon Rectum 2005;48(3):493-8.

43. Tan KY, Kawamura Y, Mizokami K,et al. Colorectal surgery in octogenerian patients - outcomes and predictors of morbidity. Int J Colorectal Dis 2009;24(2):185-9.

44. Ugolini G, Rosati G, Montroni I, et al. Can elderly patients with colorectal cancer tolerate planned surgical treatment? A practical approach to a common dilemma. Colorectal Dis. 2008;11(7):750 55.

45. Can MF, Yagci G, Tufan $T$ et al. Can SAPS II predict postoperative mortality more accurately than POSSUM and PPOSSUM in patients with colorectal carcinoma undergoing resection? World J Surg 2008;32(4):589-95.

46. Oomen JL, Engel AF, Cuesta MA. Outcome of elective primary surgery for diverticular disease of the sigmoid colon: a risk analysis based on the POSSUM scoring system. Colorectal Dis 2006;8(2):91-7. 